\title{
EL G-ZERO COMO ESCENARIO POLÍTICO INTERNACIONAL DERIVADO DE LA COVID-19
}

\author{
G-ZERO AS AN INTERNATIONAL \\ POLITICAL SCENARIO \\ DERIVED FROM COVID-19
}

Norberto Emmerich

Centro de Estudios en Estrategia y Políticas Públicas

norberto.emmerich@gmail.com

\begin{abstract}
The COVID-19 pandemic has made transparent and accentuated a series of critical elements that were already present in the international system, including the disputes between the United States and China. Questions about the future revolve around which world order will succeed the present order. Some predict a renewed multilateral order; others speak of an order in dispute repeating the international scenario of the interwar period. Finally, others speak of a decoupled world, a G-Zero scenario of distancing which is presented here as the most probable scenario. Nevertheless, it seems that globalization as we know it will no longer exist.
\end{abstract}

Keywords: Pandemic, United States of America, China, multilateralism, globalization.

\section{Resumen}

La pandemia Covid-19 ha transparentado y acentuado elementos críticos ya presentes en el sistema político internacional, entre ellos las disputas entre Estados Unidos y China. Las preguntas sobre el futuro giran en torno a qué orden mundial sucederá al orden actual. Hay quienes auguran un orden multilateral renovado; otros, un orden en disputa que repetiría el escenario internacional de entreguerras; finalmente, otros pronostican un mundo desacoplado, un escenario G-Zero de distanciamiento, lo que se presenta en este trabajo como el escenario más probable. Se concluye que la globalización como la conocemos ya no seguirá existiendo.

Palabras clave: Pandemia, Estados Unidos, China, multilateralismo, globalización. 


\section{Introducción}

El objetivo de este trabajo es describir el contexto político mundial tras la aparición del coronavirus a fin de analizar qué orden mundial sucederá al orden presente a partir de la pandemia. Ello implicará estudiar algunos aspectos como las respuestas que el sistema político internacional pudo o no ofrecer ante la problemática planteada y los cambios que se produjeron a partir de su irrupción en el escenario mundial.

Antes de que el virus apareciera en Wuhan, el mundo ya experimentaba una serie de tendencias críticas que ahora parecen acentuarse. Estas propensiones tenían que ver con la crisis de la gobernanza global, la crisis de la globalización, la crisis de la democracia liberal y la disputa hegemónica entre Estados Unidos y China (Actis y Zelicovich, 2020: 23), elementos que configuraban el escenario mundial antes de la pandemia.

Varias sociedades nacionales ya mostraban signos de disconformidad y reclamaban cambios ante las políticas aplicadas dentro del marco general del neoliberalismo, implementadas tanto por gobiernos conservadores como progresistas. El orden internacional ya estaba en aprietos desde antes (Busso, 2020: 16).

Un progresivo aislacionismo de Estados Unidos se vio profundizado con la llegada de Donald Trump a la Casa Blanca en 2016. Esta política de apartamiento o no intervención en asuntos internacionales fue evidente cuando Washington cerró el espacio aéreo a los vuelos comerciales provenientes de Europa, impidió que zarparan cruceros y cerró fuertemente la frontera con México (Rojas, 2020). No obstante, la comunidad internacional encontró esperanzas con el triunfo demócrata de Joe Biden, una atmósfera de retorno del globalismo y del multilateralismo renovado, tal como había recomendado Henry Kissinger (2020) como mecanismo de salida de la crisis pandémica.

La relativa decadencia de la hegemonía norteamericana y el ascenso de otras potencias como Rusia y China ya no era una no- vedad en el período anterior a la pandemia, sólo que ésta produjo un aceleramiento de los procesos y tendencias preexistentes. Así, se entiende la proliferación de conductas proteccionistas por parte de los gobiernos, que buscaron proteger sus mercados estratégicos frente a la competencia extranjera y las expresiones y posturas nacionalistas que derivan de ello. Sobre esta base, algunos argumentan la resurrección relativa del orden de entreguerras, una transición en disputa hacia enfrentamientos abiertos entre China y Estados Unidos.

Aunque la dinámica global y las instituciones internacionales estaban padeciendo desajustes previos, la Covid-19 ha minado las instituciones de gobernanza global al ponerse de manifiesto la ausencia de instrumentos y mecanismos capaces de establecer una acción homogénea y coordinada ante la crisis. Cada país implementó sus propias estrategias sanitarias mientras las críticas sobre el accionar de la Organización Mundial de la Salud (OMS) expusieron la desconfianza que atraviesa la Organización de las Naciones Unidas como garante del multilateralismo y su incapacidad de resolución (Maillier, 2020).

La pandemia del coronavirus ha desvanecido en tiempo récord la distancia entre las dinámicas globales y sus consecuencias individuales. Sin embargo, a falta de un gobierno global y ante la fragilidad europea, resurgen los estados-nación, los límites a la movilidad y el confinamiento, que siguen regulaciones nacionales en ausencia de directivas conjuntas (Morillas, 2020).

Aunque la pandemia dio cuenta de la cercanía entre las dinámicas globales y los individuos, la comunidad internacional y los organismos internacionales no elaboraron respuestas conjuntas para enfrentar la problemática del virus. Cada país adoptó las políticas y decisiones que consideró plausibles, la mayoría imitando un modelo de control y confinamiento, más estricto y efectivo en oriente que en occidente. Ello implica un relativo -y desigual-fortalecimiento del Es- 
tado nación y un repliegue de las instancias globales y supranacionales. En gran medida este probable, aunque no aceptado universalmente, resurgir del Estado nación fue por obligación y respuesta empírica a la contingencia, no como resultado de una estrategia de reposicionamiento global.

Cada Estado y en consecuencia e/ Estado se colocó como garante de la salud de sus habitantes y a cargo de la gestión de la crisis. Si los líderes se hubieran reunido en el Consejo de Seguridad o en el G-20 y hubieran prometido grandes fondos para que los países pobres pudieran afrontar el coronavirus -en vez de repartirse culpas recíprocamente- todos estaríamos mucho mejor (Nye y Renedo, 2020). Pero no fue así.

En Europa, el resurgimiento del rol del Estado resucitó las fronteras

restringiendo las libertades de movimiento asociadas al mercado único y a Schengen. Algunos incluso prohibieron la exportación de material médico a Italia, anticipándose a la protección de su ciudadanía, también en clave nacional, y por encima de las reglas del mercado interior. $Y$, por supuesto, el populismo sacó rédito político del coronavirus, con Boris Johnson actuando a su manera para contener la curva de contagios, Trump refiriéndose al virus chino y Orbán, Salvini y Le Pen llamando al cierre de fronteras (Morillas, 2020).

Lo anterior constituye un repertorio diferente y desigual de decisiones, opciones y perspectivas donde la categoría de fortalecimiento del Estado nación queda desmerecida e incógnita. Si bien los Estados nacionales son los articuladores del sistema internacional desde 1648 frente a instituciones internacionales débiles y cambiantes que no llegan todavía al primer siglo de historia, las respuestas internacionales a la pandemia no estuvieron totalmente ausentes, al menos en tres instancias:

1. Una es la OMS y su rol de directriz.

2. Otra fueron las cadenas globales de valor, que en muchos casos específicos se han comportado con mayor eficiencia y velocidad que los propios Estados.

3. La tercera son los eventos deportivos y ferias, cuya cancelación depende de decisiones adoptadas en instancias internacionales.

Por otra parte y en menor grado, algunos elementos de solidaridad internacional se hicieron presentes cuando China ofreció a Italia y a España equipamiento médico (Morillas, 2020) junto con otras conductas de solidaridad internacional que diversos actores han realizado. Sin embargo, estas conductas de coordinación y de solidaridad fueron aisladas y no se convirtieron en el vector principal de la conducta internacional en el contexto de pandemia.

\section{Un mundo en transformación, la idea de orden multipolar renovado}

El nuestro es un mundo que se encuentra ahora marcado por la incertidumbre; es lógico que se tienda a pensar en futuros contrapuestos: algunos entienden que el escenario pos-pandemia mostrará un mañana totalmente nuevo, otros argumentan que nada cambiará (Busso, 2020: 6). Lo cierto es que los rasgos preponderantes del orden mundial previo, es decir, la crisis de la gobernanza global, la crisis de la globalización, la crisis de la democracia liberal y la disputa hegemónica entre Estados Unidos y China, seguirán presentes en el nuevo orden al mismo tiempo que se agregan nuevos elementos en curso cuyo desarrollo se irá constituyendo a través del tiempo.

El principal elemento nuevo es el distanciamiento, una conducta generalizada a nivel individual que se está trasladando a los comportamientos comerciales internacionales y quizás se involucre en las dinámicas de la política internacional. En la yuxtaposición del orden mundial previo con el orden mundial naciente se irán conformando las características de lo que se denomina decoupling, un mundo regionalizado en pocas grandes porciones unidas entre sí, pero separadas del resto. Es un escenario nuevo en 
la medida que no se trata de la guerra fría y su orden bipolar rígido, sino de una paz caliente con un mundo desacoplado pero flexible.

Busso argumenta que un orden internacional está conformado por un conjunto de reglas y expectativas en torno a los cuales actúa una sociedad de estados (2020: 8). Independientemente de si los actores no estatales conforman o no el orden internacional, lo cierto es que la idea de orden invoca regularidades, estabilidad, consenso y reglas de juego aceptadas. Todo relativamente, por supuesto.

Desde las guerras napoleónicas los cambios significativos en la distribución del poder han sido consecuencia de guerras, como sucedió con los órdenes surgidos después de la Primera y Segunda guerras mundiales, así como la Guerra Fría.

Henry Kissinger afirma que el cambio de orden deriva de dos circunstancias posibles que lo desafían: la redefinición de la legitimidad o un cambio significativo en el equilibrio del poder.

En relación con la redefinición de la legitimidad, no estamos todavía ante una situación de delimitación del orden mundial creado tras la Segunda Guerra Mundial y la Guerra Fría. Dicho orden está sostenido en una relación transatlántica que afronta muchas dificultades, pero los valores de la democracia liberal no han sido abandonados (Milosevich, 2020).

Otros dicen que, en una marcada desviación de la sabiduría predominante de las últimas décadas, ya estamos presenciando el regreso del Gran Gobierno. Esto no sugiere que se abolirá la economía de mercado, pero el Estado se hará respetar frente a la comunidad empresarial, al menos cuando se trate de cuestiones estratégicas (Fischer, 2020).

En cuanto a un cambio significativo en el equilibrio del poder que podría afectar al orden liberal, éste ya se estaba gestando antes de la pandemia. China representó el principal desafío, porque era difícil que su expansión se acomodase a una tensión estable con Estados Unidos. Es una tenden- cia que llamativamente puede ralentizarse más que acelerarse, ya que una de las consecuencias más previsibles de la Covid-19 será la desacoplación (decoupling). Estados Unidos y la UE procurarán depender económicamente menos de China, lo que debilitará su poder y su capacidad de influir en las relaciones internacionales (Milosevich, 2020). Los síntomas de desacoplamiento son evidentes en la cadena global de suministros, donde las grandes empresas están produciendo sus propios insumos en porcentaje creciente o importándolos de proveedurías cercanas. En la frontera norte mexicana la ocupación de mano de obra durante la pandemia cayó abruptamente, como en todos lados, pero ya se recuperó con superávit en virtud de las nuevas inversiones de la cadena global de suministros.

Uno de los principales aspectos con que el orden global enfrenta la pandemia es la falta de coordinación política global ante el avance del virus (Lissardy, 2020). Es de afirmación común que esta ausencia tiene que ver con la retirada y el vacío de liderazgo que adoptó Estados Unidos bajo la administración de Donald Trump, quien llegó a la presidencia con la consigna de "America First", al igual que lo hizo el presidente Warren Harding en 1920 prometiendo "volver a la normalidad" tras la Primera Guerra Mundial. Este enfoque unilateral y nacionalista va en sentido contrario a la postura de líder global que Estados Unidos asumió desde la Segunda Guerra Mundial.

Un segundo aspecto importante a analizar es la posibilidad de cambios en el orden global y la probable ascensión de un nuevo líder hegemónico mundial, un rol en el que se considera a China como principal aspirante. A ese respecto, Ian Golding, de la Universidad de Oxford, dice que China no puede asumir el rol vacante de Estados Unidos en el liderazgo mundial (Lissardy, 2020).

En el primer aspecto, referido al impacto de la pandemia, es innegable la capacidad de deterioro y destrucción que ha tenido sobre las economías nacionales y la economía mundial, con fuertes consecuencias en la vida social y política. 
En el caso de Estados Unidos, la pandemia vino a interrumpir más de una década de crecimiento económico (128 meses consecutivos, de junio de 2009 a febrero de 2020), en la que, pese a ser menos robusta que los ciclos anteriores, fue la expansión más larga jamás registrada en los Estados Unidos (CEPAL, 2020).

El colapso del empleo es de una magnitud sin precedentes y es probable que alcance o supere el de cualquier recesión ocurrida en los últimos 150 años.

El período más largo de creación de empleos en la historia de Estados Unidos -113 meses consecutivos- tuvo un final abrupto en marzo de 2020, cuando se perdieron 870.000 puestos de trabajo a causa de la pandemia. La tasa de desempleo saltó al $14.7 \%$, del $4.4 \%$ registrado en marzo y el $3.5 \%$ de febrero, que había sido la más baja en 50 años (CEPAL, 2020).

En el segundo aspecto, sobre los cambios en el orden global, Goldin (en Lissardy, 2020) es uno de los expertos que plantea una disyuntiva entre dos escenarios globales similares a las posguerras, que pueden ser un mundo fragmentado, con crecientes divisiones o un mundo con mayor cooperación internacional, como un retorno a una globalización renovada, lo que parece encarnar la presidencia de Joe Biden en Estados Unidos, un cambio de gobierno que ayudará a percibir un escenario mundial de mayor involucramiento americano, lo que coincide con los primeros pronunciamientos del presidente.

Arturo Valenzuela, quien fuera subsecretario adjunto del Departamento de Estado con Barack Obama, afirma que "lo que hay que tratar de ver es cómo con alianzas, con instituciones internacionales que se están renovando, podamos encarar los desafíos que tenemos por delante" (BCN, 2020). Propone el acuerdo como un mecanismo para evitar caer en la trampa de Tucídides, es decir, lo que pasa cuando hay una potencia dominante que se encuentra con una potencia que la está desafiando, porque generalmente cuando aparece una potencia emergente, la solución es la guerra.
En este sentido, Bill Gates opina que Estados Unidos tenderá al involucramiento internacional. "Hay muchas voces que nos empujarán a trabajar con Europa y con otros países y ser parte de las innovaciones que pondrán fin a esto", sostiene el filántropo multimillonario en el portal informativo Vox (Lissardy, 2020), o sea, un escenario similar al del fin de la Segunda Guerra Mundial.

Hay quienes afirman un panorama más sombrío y advierten que la falta de involucramiento activo de Estados Unidos, un declive económico histórico y las tensiones entre los países, anuncian un panorama similar al período de entreguerras (Lissardy, 2020), con una situación internacional en deterioro progresivo.

Saskia Sassen favorece la idea de un escenario intermedio y afirma que "habrá algunos actores importantes, en particular Estados Unidos, que irán hacia crecientes nacionalismos, pero una vez que (Trump) esté fuera, puede haber distintos escenarios en juego" (Lissardy, 2020). Voces como la de Angela Merkel pueden influir para que el mundo retome el camino del acuerdo y el multilateralismo.

Finalmente, Salvoni (2020) afirma que el mundo se encamina hacia una nueva etapa de bipolaridad, aunque diferente a la experiencia vivida en la Guerra Fría porque dos potencias se están disputando el liderazgo global, no hay duda de ello. Pero China no cuenta con la capacidad económica ni con las capacidades de soft y hard power que le permitan influir en todos los escenarios globales como lo hace Estados Unidos, el único poder global todavía existente, aunque con desgaste y cansancio. El despliegue de soft power implementado por China es parte del largo camino que deberá recorrer para constituirse como líder mundial.

El retroceso del multilateralismo y de la cooperación no implica una pérdida de poder real de Estados Unidos. Habrá que ver la capacidad de adaptación de la política exterior estadounidense, que determinará los efectos que el nuevo contexto global tenga en sus capacidades reales de proyección de poder. Estados Unidos continúa siendo la 
mayor potencia económica y militar a escala global, lo que lo sitúa en una posición de ventaja frente a cualquier país que pretenda desafiarlo (Salvoni, 2020).

\section{El retorno de lo político y la recuperación del Estado}

Diversos elementos que abonan la idea del retorno del Estado al centro de la escena son compatibles con una visión optimista de resurrección del orden multilateral porque el retorno del Estado cobija la noción de un mayor margen de acción para los Estados más fuertes, capaces de timonear el orden mundial. La pérdida de confianza y la sensación del público de la incapacidad de protección del gobierno en turno han permitido un retorno de lo político, regresando al Leviatán de Hobbes y a una comprensión de la importancia de un Estado fuerte que proteja a sus ciudadanos (Chacón et al., 2020).

En América Latina y el Caribe es natural que haya una tendencia a preocuparse por el autoritarismo, especialmente por el pasado que comparte la región. Por esto, las preocupaciones sobre los retrocesos pueden estar agudizadas (Chacón et al., 2020).

Incluso antes de la pandemia algunos gobiernos democráticos y electos por las urnas han demostrado que están dispuestos a usar mano dura frente a la sociedad civil, como han sido las respuestas de los gobiernos de Bolivia, Chile y Ecuador frente a las manifestaciones sociales en 2019 (Chacón et al., 2020).

Otros piensan exactamente lo contrario: argumentan que la irrupción de las nuevas tecnologías ha favorecido que la política exterior deje de tratarse como un coto privado de los gobiernos, lo que implica un menor poder para el monopolio de la burocracia estatal tradicional. En palabras de la periodista Esther Dyson, se ha producido la "desintermediación de los gobiernos" (Torres, 2020).

Mientras que la directora gerente del Fondo Monetario Internacional (FMI), Krystalina Giorgieva, dijo que "para proteger la salud pública, la economía mundial entró en situación de estancamiento" (FMI, 2020) como si el confinamiento global hubiera sido la más sabia de las respuestas y no un ataque de pánico generalizado, hay quienes afirman que "el cese de actividades y la crisis de salud no sólo han evidenciado las fallas del sistema de salud pública de Estados Unidos, sino las fallas del Estado en general" (Chacón et al., 2020).

Ante una crisis con fuertes dimensiones subjetivas y emocionales, el discurso del distanciamiento o el aislamiento no sería el más indicado y más bien habría que apostar a espacios de reflexión, encuentro y tramitación colectiva de la situación.

Pero Milton Friedman afirmó que, ante una crisis, las acciones que se llevan a cabo dependen de las ideas que "flotan en el ambiente" (Vommaro, 2020), con lo cual las respuestas tienden a repetir lo que se ha hecho en ocasiones anteriores ante problemas similares, basadas en un reservorio de ideas comúnmente aceptadas.

En el caso de que se acepte la idea de pérdida de poder de los Estados, cabe preguntarse si en un futuro inmediato habrá que enfrentarse a la desaparición de algunos de ellos, sobre todo en zonas marginales. Esto podría dar paso a una realidad indeseada, con un vacío de poder político global y una consecuente falta de orden.

Es probable que la responsabilidad de los Estados más potentes, en detrimento de la ausencia de la comunidad internacional, exigirá que actúen al respecto, yendo más allá del derecho de injerencia. Puede que resurja una nueva forma de neocolonización, bajo la forma de la privatización de los Estados inviables en manos de los más poderosos o incluso de actores no estatales (Torres, 2020).

\section{El sistema internacional}

Una evaluación de la capacidad de respuesta del multilateralismo conduce al sistema de la Organización de las Naciones Unidas, empezando por su Consejo de Seguridad. Es evidente la flagrante resistencia de este 
órgano a reconocer que la pandemia actual requiere respuestas similares a las de anteriores situaciones (Malacalza y Hirst, 2020).

Es fácil ver un grave debilitamiento del sistema multilateral. Los ataques en forma de "atribución de culpas" a instituciones como la Organización Mundial de la Salud y la Organización de las Naciones Unidas además de la ineficacia del G-7 a la hora de tomar acciones concretas, vienen auspiciados por Beijing, Moscú y Washington.

La ineptitud y las mentiras de las dos superpotencias -Beijing y Washington- que "proyectan sentido", según la expresión de Zaki Laidi, no es más que la continuación por otros medios de la lucha entre potencias y están llevando a la ruina al sistema multilateral (Chacón et al., 2020). El lugar estelar ha sido ocupado por la OMS, que gracias a su protagonismo ha contribuido a colocar en un lugar privilegiado la narrativa científico-humanitaria sobre el nuevo coronavirus (Malacalza y Hirst, 2020).

El mayor contribuyente de la OMS es Estados Unidos (15-16\%), el cual ha recortado el financiamiento, causando un grave daño sobre todo para los países que no tienen capacidades para responder a esta situación. El segundo mayor contribuyente es Bill Gates, quien anunció que iba a aumentar su contribución cuando Estados Unidos anunció que iba a disminuir la suya, lo mismo que hizo China. Otros países han tratado de llenar vacíos, pero las capacidades son limitadas (Astroza Suárez, 2020).

\section{La inhabilidad americana y europea, la idea de orden en disputa}

La pérdida de capacidad de liderazgo de Estados Unidos se ha revelado como una de las características más sobresalientes de la vida cotidiana del sistema mundial en los tiempos de esta pandemia. Como contracara de este proceso, se observa el ascenso de China como potencia global, posición anclada en esfuerzos cooperativos de combate al nuevo coronavirus que se suma a la presencia económica y tecnológica conquistada en los años anteriores (Malacalza y Hirst, 2020).
La retracción del multilateralismo ha estado asociada a la crisis del internacionalismo liberal y a la crisis de hegemonía de Estados Unidos, que arrastra consigo la postración y fatiga del ideario wilsoniano.

Actualmente, Estados Unidos tiene todo el poder y los factores relacionados para aunar voluntades en la lucha contra la pandemia y para crear la vacuna o tratamiento, pero no tiene la voluntad política suficiente y por ello queda un vacío (Astroza Suárez, 2020).

Estados Unidos manejó la pandemia puertas adentro y renunció a liderar las respuestas globales al problema, dejando el espacio libre para el desempeño de otros actores internacionales, una ausencia del escenario mundial que ha sido significativa.

El aislamiento americano implicó apelar a la ley de Producción de Defensa -que data de la Guerra de Corea- para obligar a General Motors a iniciar la fabricación de respiradores o prohibir que la compañía 3M continuara exportando mascarillas N95 y guantes quirúrgicos a clientes en el extranjero (Rojas, 2020).

China tuvo otro comportamiento y logró reducir el número de contagiados y fallecidos, a pesar de que la comunidad de inteligencia de Estados Unidos asegura que Beijing ha manipulado las cifras. A diferencia de Washington, se ha transformado en la potencia que está enviando insumos médicos a países como Italia y Venezuela, así como profesionales de la salud dispuestos a compartir su experiencia en el combate al coronavirus (Rojas, 2020).

Esto pone a Beijing nuevamente en ruta de colisión con Washington por el liderazgo global, porque además de ser la segunda economía más importante del planeta, China aprovechará esta crisis para reforzar su posición en zonas como África, América Latina y el Sudeste Asiático a través de la asesoría médica, la entrega de préstamos a los países más afectados y la masificación de su tecnología $5 \mathrm{G}$ y de Beidou, su sistema de posicionamiento global (Rojas, 2020).

Por el lado ruso, el presidente Vladímir Putin aprovechará la situación para fortale- 
cer su esfera de ascendiente en Europa del Este y aumentar su influencia sobre una debilitada Unión Europea, a través de sus exportaciones de gas (Rojas, 2020).

Es probable que los globalizadores, una vez que se haya superado el período de pico de muertes y contagios, intenten restablecer varias pautas de la globalización neoliberal preexistente (Busso, 2020: 16). Es la razón de ser del gobierno de Joseph Biden. Por otro lado, una desglobalización total es imposible, porque hay estructuradas globalizadas socialmente aceptadas, pero un retroceso marcado hacia el nacionalismo y la región es un escenario muy probable.

La Unión Europea no se mostró unida ante la pandemia. España e Italia, que se convirtieron en los primeros focos de la pandemia en suelo europeo, plantearon la idea de que el costo del combate a la Covid-19 se prorrateara entre todos los miembros de la Unión Europea -los Ilamados "coronabonos"- ante lo cual países como Alemania y Holanda se manifestaron en contra (Rojas, 2020). Esto no es sorprendente porque en las crisis existenciales, las personas tienden a volver a lo que mejor saben, y lo que mejor saben es el Estado-nación (Fischer, 2020).

Esta crisis ha reflotado la antigua tensión norte-sur dentro de la UE que, durante la crisis del euro en 2010, quedó de manifiesto cuando economías como la alemana, la francesa y la británica se resistieron a la idea de salvar a socios del Mediterráneo, como Grecia, Portugal, España e Italia (Rojas, 2020).

La actual crisis evidenció la dificultad de la UE para operar como un todo, porque las decisiones emanadas de Bruselas tuvieron un peso menor que las adoptadas por los gobiernos de cada país, fortaleciendo el individualismo nacional y debilitando la UE (Rojas, 2020). No son pocos los que ya hablan de esta crisis como "la pandemia de la desglobalización” (Rojas, 2020). Estos elementos abonan la idea de un orden en disputa, el segundo escenario presentado en este trabajo, que consideramos poco probable.

\section{Promesas de un futuro mejor, cargadas de continuidad apocalíptica}

La pandemia ha tensado las relaciones entre el Estado y la sociedad, empujando a los gobiernos autoritarios a adoptar medidas cada vez más antidemocráticas. En muchos países, la libertad de prensa ha sufrido las consecuencias de la pandemia. En un mundo cada vez más digital, existe mayor margen para la difusión de noticias falsas y desinformación. Tanto Rusia como China han desplegado una intensa labor de comunicación en torno a la Covid-19 con sus propios métodos y campañas de desinformación. La crisis sanitaria ha dado origen a una preocupación por la posibilidad de que la desinformación, unida a una diplomacia sanitaria agresiva, se utilicen para ejercer una mayor influencia geopolítica, tanto al interior de los países como formando parte de su política exterior. En general, los expertos también están de acuerdo en que las amenazas informáticas se multiplicarán. Europol informa que la delincuencia informática avanzará y que la posibilidad de que se cometan ciberataques graves aumenta a medida que recrudece la competencia geopolítica (Lazarou, 2020).

Mientras el FMI proyectaba que la actividad económica mundial disminuiría en una escala no registrada desde la Gran Depresión (FMI, 2020), las dimensiones del problema ameritaron la intervención de bancos centrales, gobiernos e instituciones multilaterales.

La directora del FMI detalló diversas operaciones de ayuda implementadas por el FMI ante la pandemia y concluyó que "en colaboración con el Banco Mundial, también hicimos diligencias para que se suspendan hasta el final de 2020 los reembolsos de la deuda oficial bilateral de los países más pobres" (FMI, 2020). Al anunciar que el futuro puede ser mejor, dice al mismo tiempo que la suspensión de la deuda para los países pobres será de algunos pocos meses, a todas luces un apoyo insuficiente. 


\section{También sostuvo que}

las distorsiones en las prioridades de gasto menoscabarán la recuperación y los esfuerzos que se realicen a largo plazo para fomentar el crecimiento sostenible e inclusivo, o para elevar la productividad y los niveles de vida. Nuestro mensaje a los gobiernos es claro: hagan todo lo que sea posible, pero asegúrense de guardar los recibos. No queremos que la rendición de cuentas y la transparencia queden relegadas a un segundo plano (FMI, 2020).

Los argumentos que forman parte del problema siguen repitiéndose a la hora de aportar soluciones, todo dentro de una lógica de ajuste y contención. Esta era la lógica que funcionaba en las instituciones multilaterales previamente a la pandemia y que definía el contenido de esa multilateralidad, indicios de que las dificultades del multilateralismo se volverán a repetir si pretende reasumir sin cambios drásticos las posiciones perdidas.

En este futuro cuyos contornos se desconocen, algunos hablan de las proxy wars o guerras por delegación, un recurso habitual de las grandes potencias. Según el diccionario de Cambridge, una proxy war es "una guerra luchada entre grupos o países pequeños que representan los intereses de otras potencias más poderosas, y que puede que reciban apoyo de estas" (Torres, 2020), como si pudiéramos hablar de guerras de franquicias.

Es un escenario que ha contribuido al deterioro del multilateralismo y al aumento de la incertidumbre sobre las características de un nuevo orden post Covid-19, un contexto en el que Ian Bremmer ha planteado la posibilidad de un mundo "G-Zero" o "cero-polar", en el cual ningún país o alianza permanente de naciones puede asumir un liderazgo mundial. Derivado de ello, la cooperación internacional se encuentra decreciendo, avizorando nuevos conflictos económicos y una tendencia hacia el proteccionismo, lo que es posible observar principalmente en Estados Unidos y Europa (Rojas, 2020).
Si estamos viendo elementos propios de un mundo G-Zero se trataría de un interregno, un punto de detención, un vacío geopolítico del orden mundial, lo que podría denominarse una recesión geopolítica "que no creo que dure para siempre, pero que sí por al menos 10 años. Pero las consecuencias todavía no las conocemos, no sabemos cómo será el mundo post orden mundial americano" (Rojas, 2020).

\section{Decoupling en la cadena global de suministros-CGS}

El entendimiento sobre el orden internacional venidero cobra mayor luz al analizar el comportamiento de la cadena global de suministros y su acercamiento a lo que se denomina decoupling o desacoplamiento, un escenario que traducido al orden internacional de Estados coincide con la perspectiva de orden G-Cero.

Antes del brote de la pandemia de Covid-19 ya había claros signos de cambios en el comercio mundial. Con su fuerte estrategia interna del America First y el consecuente decoupling entendido como el desacoplamiento y la repatriación de inversiones y procesos productivos, Estados Unidos dio paso hacia un escenario de incertidumbre. Debido a sus rivalidades geopolíticas con China, pero también al formato agresivo frente a la Unión Europea, se agregaron nuevas fricciones e incertidumbre. Quedó entonces evidenciada la fragilidad de las cadenas globales e integradas de valor bajo las actuales condiciones políticas (Lange, 2020).

La digitalización de los procesos productivos modifica la división del trabajo tradicional y pone en jaque las cadenas de suministro, otorgando cada vez mayor prioridad a las tecnologías digitales y a la cercanía al cliente. El big data y las impresoras 3D flexibilizan mucho más la producción y traen consigo nuevas opciones regionales y locales.

Al reorganizar el flujo de bienes se hace mayor hincapié en las competencias internas de la empresa y se restituye la creación 
de valor a los fabricantes de equipamiento original (OEM, en inglés) en los países industrializados. Algunos componentes centrales del Model 3 de Tesla son producción propia, sin suministros de los proveedores de sistemas. Este desarrollo autónomo de soluciones de hardware y de software por parte de Tesla muestra que en ocasiones pueden ser innecesarias las cadenas de valor impulsadas hasta ahora. La división del trabajo tradicional presente en ellas quizás haya afectado la capacidad de innovación (Lange, 2020) en aras de mejorar la seguridad y la logística.

Según el estudio "Una nueva era del comercio mundial", realizado por la Universidad Técnica de Münich, las cadenas internacionales de suministro ya se encontraban en una fase de retroceso o estancamiento (Lange, 2020).

La adopción generalizada de medidas de confinamiento dejó en evidencia la fragilidad de las cadenas de valor en la producción de bienes. El riesgo se eleva porque a la estructura global de las cadenas de suministro se suma que las empresas redujeron su cantidad de proveedores y hoy cuentan a veces con uno solo para abastecerse de determinadas piezas y sistemas (Lange, 2020). Lo más probable es que las empresas reorienten de manera acelerada sus cadenas de suministro y procesos de producción para robustecer las cadenas de valor, las que además podrían acortar sus distancias. Las compañías apuntarán a diversificar las estructuras de suministros y generar redundancias (segunda fuente), reducir los esquemas basados en el just in time y restablecer mayores capacidades de almacenamiento.

Este panorama implica un retroceso de la estrategia habitual de globalización que consistía en trasladar todo hacia el lugar donde la producción tuviera la máxima eficiencia.

\section{Conclusiones}

Como una reacción frente a la pandemia en el centro europeo, países como Francia,
Alemania o Italia se lanzaron contra la Europa de Schengen y pedían el cierre de fronteras desde el primer momento, alimentando la idea de la pandemia como una amenaza exterior (Fabelo Concepción, 2020). Esas conductas reactivas propias de un orden en disputa no fueron el vector principal de comportamiento de los Estados, más volcados al sálvese quien pueda que a emprendimientos condenatorios activos de los peligros provenientes de otros países.

Sin embargo, es probable que en el mundo post pandemia permanezca el endurecimiento de las políticas migratorias y el aumento de los controles fronterizos como una de las maneras de evitar la llegada de contagiados o de frenar la expansión de eventuales mutaciones de este mismo virus (Rojas, 2020) o de otros. Estas políticas atentatorias del derecho al libre tránsito de las personas, consagrado en las constituciones nacionales, se aplican también al interior de las fronteras nacionales, impidiendo el tránsito de personas desde una localidad a otra del propio país, o incluso el traslado dentro de la misma ciudad.

En el futuro próximo es muy probable que la Organización de las Naciones Unidas sea objeto de profundos cuestionamientos, principalmente por el desempeño de la OMS durante la pandemia (Rojas, 2020).

Keohane y Nye hablaban de los conceptos de sensibilidad de las respuestas y la vulnerabilidad ante los acontecimientos entre los Estados como una forma de medir la interdependencia. La pandemia manifestó que la sensibilidad fue muy lenta y que la vulnerabilidad fue muy alta, demostrando que los Estados son los únicos que pueden garantizar un mínimo de estabilidad en épocas de crisis. La medida más común adoptada en todos lados fue la cuarentena en los países más afectados por el virus. China tuvo la ventaja de un gobierno autocrático que no debe rendir cuentas. Otro es el caso de Donald Trump, que con las elecciones en noviembre (UCSF, 2020) perdió el gobierno.

Es claro que el ordenamiento internacional actual tiene una jerarquía en la importancia de sus cuestiones y la salud no es una 
prioridad. Las posturas disímiles que ha generado la lucha contra la Covid-19 demuestran una falta de liderazgo a nivel internacional (UCSF, 2020).

El sistema político internacional actual está haciendo frente a esta crisis de manera descoordinada. La histórica nación protagonista en la coordinación y ayuda en situaciones de crisis como la presente, decide actuar de otra manera y no colaborar con el sistema internacional. Por el otro lado, China está fortaleciendo su imagen de líder global y generando cierta bonanza internacional (UCSF, 2020).

Washington, que ha actuado como policía mundial desde la Segunda Guerra Mundial, está provocando que muchos de sus socios y aliados se pregunten ahora si pueden contar con que lidere la respuesta a una crisis global, una inquietud que sigue teniendo hasta el momento una respuesta negativa. El flamante presidente Joseph Biden busca convencer al mundo de que Estados Unidos pretende atender seriamente las preocupaciones comunes.

Las tensiones diplomáticas han reaparecido súbitamente: mientras el gobierno turco retenía respiradores artificiales destinados a España, Francia hacía lo mismo con las mascarillas. Algunas fronteras se cierran y otras se refuerzan con tanques, mientras se negocia la repatriación de sus ciudadanos. Los medios chinos informaron sobre un posible freno a las exportaciones de equipos de protección personal (EPP) chinos buscando presionar a Washington para aliviar sus sanciones contra Huawei (Sánchez Chumpitaz, 2020).

Según el filósofo surcoreano ByungChul Han, autor de La sociedad del cansancio, en Asia y especialmente en China, las personas son menos renuentes y más obedientes que en Europa y confían más en el Estado. Así también en Corea o en Japón la vida cotidiana está organizada mucho más estrictamente que en Europa. Para enfrentar al virus los asiáticos se decantan fuertemente por la vigilancia digital, apuestan a que el big data encierra un potencial enorme para defenderse de la pandemia.
Se puede decir que en Asia las epidemias no las combaten sólo los virólogos y epidemiólogos, sino también los informáticos y los especialistas en macrodatos (Fabelo Concepción, 2020), lo que supone un comportamiento más estatal que en occidente, poniendo en juego los amplios recursos de los que todo Estado dispone, no sólo un espectro limitado de ellos.

El entonces presidente Donald Trump dio un enfoque político al tema, al identificar la pandemia como "el virus de China", proveyendo a la crisis de un discurso de fronteras, antiinmigrante y llamando a reactivar la economía del país (Fabelo Concepción, 2020).

La sensación de emergencia global que la Covid-19 ha generado no es una crisis que la ciencia y algunas instituciones no hayan previsto. De hecho, las naciones podrían haber estado mejor equipadas para enfrentar la pandemia por el simple hecho de que se había previsto la posibilidad de la misma. Sin embargo, los Estados nacionales no han seguido un protocolo definido y cada uno de ellos adoptó su propia estrategia (CARI, 2020).

No se entendió que ni un solo país puede estar seguro hasta que todos los gobiernos controlen la pandemia. Todos los países coinciden en que su principal objetivo es erradicar la Covid-19, pero la falta internacional de coordinación y cooperación, al menos al comienzo de la pandemia, ha fortalecido al enemigo común (CARI, 2020).

En medio de la pandemia, el presidente de los Estados Unidos anunciaba el retiro de fondos a la OMS, lo que significaba prácticamente su desmantelamiento (CARI, 2020), pero que evidenciaba la absoluta falta de solidaridad, coordinación y búsqueda del bienestar común. El secretario general de Naciones Unidas, António Guterres, destacó que "la pandemia actual es la prueba más grave desde la fundación de la ONU, lo que representa una amenaza significativa para el mantenimiento de la paz y la seguridad internacionales que también puede conducir a un aumento de los disturbios sociales y la violencia”, buscando involucrar al 
Consejo de Seguridad de la ONU en la lucha global contra la Covid-19 (CARI, 2020).

Estas angustias revelan el regreso a la demanda de la función estatal, tanto para fortalecer los debilitados sistemas de salud pública como para que el presupuesto público sostenga a la estructura privada, financiera e industrial, como en los viejos tiempos.

El austericidio del que habla el ex presidente español Felipe González tiene su partida de nacimiento en Berlín y en la cultura del ajuste que se afianzó después de la crisis del 2008. El regreso a la mano visible del Estado ha convertido a todos en socialdemócratas. Ese proceso de ajuste perpetuo expuso los costos de haber abandonado las enseñanzas de otras tragedias igualmente brutales, pero de naturaleza diferente, como las dos grandes guerras del siglo $X X$ (Cantelmi, 2020).

Los efectos de la crisis de 2008 acentuaron la miopía propia de un concepto que financistas y especuladores como George Soros han Ilamado codicia corporativa. El ingreso y la renta se concentraron a niveles nunca vistos, empujando fuera del ciclo de distribución a enormes sectores de las poblaciones nacionales.

La asistencia financiera que está fluyendo a distinta escala en los países, aunque insuficiente, es bienvenida. Pero estos dineros no ayudarán a reactivar las economías con más consumo y producción porque el mundo está paralizado.

Hemos afirmado que poco antes de la aparición de la pandemia a fines de 2019, se produjo una serie de grandes protestas sociales a nivel global. Esos levantamientos civiles en Latinoamérica, Europa, el espacio árabe y Asia reaccionaban al estrechamiento incesante de la distribución de la renta, proceso que se agudizó en la última década. La pandemia desvió el proceso apenas un poco, para enfocarlo en la crisis social subyacente en las grandes economías, con detonantes políticos y alcance internacional. Los hechos del 6 de enero en el Capitolio americano desnudan la crisis interior y alimentan la crisis hegemónica.

El daño social es inevitable y crece en proporción directa a las medidas de aislamiento y contención que se adoptan para impedir que el virus se esparza. El resultado siguiente que ya comienza verse es el fortalecimiento del perfil autoritario de los gobiernos enfrentados a la enfermedad y temerosos del descontrol doméstico. En Estados Unidos se han multiplicado las protestas de los empleados de las automotrices, del transporte, de los grandes almacenes de alimentos, del campo y de Amazon rechazando las condiciones inseguras del trabajo y el creciente desempleo (Cantelmi, 2020).

Algunos gobiernos preocupados por ese escenario han desarrollado un panóptico de vigilancia con alcances insospechables (Bautista, 2020). Israel aplica a los civiles comunes las estrategias tecnológicas creadas para la guerra contra la minoría palestina (Castillo, 2020).

España e Italia instaron a los miembros de la eurozona a mutualizar las deudas mediante la emisión de eurobonos, un instrumento que contaría con el respaldo y garantía de todos los miembros de la zona euro. Pero algunos países -Alemania, Holanda, Finlandia y Austria- se negaron con el argumento de que era un intento encubierto de las naciones meridionales para beneficiarse de ayudas a bajo precio financiadas por los Estados con presupuestos equilibrados. La respuesta era que cualquier ayuda de esa índole debería ir acompañada de un plan de ajuste de las economías, atacando el incendio con combustible (Lafraya, 2020).

La batalla que han venido librando las dos mayores economías del planeta no es sólo comercial, como sostiene el discurso norteamericano. El eje de ese choque es el control en un futuro muy próximo de las tecnologías estratégicas, desde telecomunicaciones con el G5, que ya encabeza Beijing, hasta robótica, equipamiento medicinal y super computadoras (Cantelmi, 2020).

Este enfrentamiento debe verse a la luz de un conjunto unificado de variables, junto con las tendencias aislacionistas de todos los países (alimentadas entre otras cosas por el temor al virus) más el ascenso del rol de gobierno, todo lo cual tiende a la con- 
figuración de un mundo fragmentado en grandes bloques, con relocalización de empresas, acceso a recursos provenientes de la geografía cercana y una cadena de abastecimiento más corta.

\section{Fuentes consultadas}

Actis, Esteban y Zelicovich, Julieta (2020), "El ritmo básico de reproducción del Covid 19 en la transformación del sistema internacional", en Anabella Busso (comp.), Relaciones Internacionales en tiempos de pandemia, Rosario, Centro de Investigaciones en Política y Economía Internacional (CIPEI)-Universidad Nacional de Rosario.

Astroza Suárez, Paulina (2020), "Política internacional en tiempos de Covid-19", ponencia presentada en la sexta sesión de Ciclos de Webinarios en Tiempos de COVID-19 el 27 de mayo de 2020, Universidad de Concepción, Chile, Concepción, <https://bit.ly/2QT9At4>,15 de enero de 2021.

Bautista, Rafael (2020), "La pandemia viral como principio del panóptico global", América Latina en movimiento, 24 de marzo, Opinión, <https://bit.ly/3vHFHKU>, 22 de enero de 2021.

Biblioteca del Congreso Nacional de Chile (BCN) (2020), "Expertos destacaron rol de China en el escenario internacional post pandemia", Santiago de Chile, Biblioteca del Congreso Nacional de Chile, <https://bit.ly/3b25TYT>, 19 de enero de 2021.

Busso, Anabella (2020), "Pandemia y orden internacional: incertidumbre entre lo viejo que no quiere morir y lo nuevo que no termina de nacer" en Anabella Busso (comp.), Relaciones Internacionales en tiempos de pandemia, Rosario, Centro de Investigaciones en Política y Economía Internacional (CIPEI)-Universidad Nacional de Rosario.

Cantelmi, Marcelo (2020), "El mundo en la era del coronavirus", Observatorio de Política Internacional, Palermo, Univer- sidad de Palermo, <https://bit.ly/2QTc5LY>, 21 de enero de 2021.

Castillo, María del Pilar (2020), "La nación del startup recurre a la tecnología y tests masivos para combatir al coronavirus", La Nación, 31 de marzo, Buenos Aires, El Mundo, <https://bit.ly/2RkAUjM>, 22 de enero de 2021.

Chacón, Rodrigo; Saltalamacchia, Natalia; Sberro, Stéphan; Granados, Ulises y Goodliffe, Gabriel (2020), "Los alcances políticos del Covid-19 a nivel mundial", México, Foreign Affairs Latinoamérica, <https://bit.ly/33gbs1u>, 20 de enero de 2021.

Comisión Económica para América Latina y el Caribe (CEPAL) (2020), "Impacto del Covid-19 en la economía de los Estados Unidos y respuestas de política", CEPAL, <https://bit.ly/2PMAsKC>, 20 de enero de 2021.

Consejo Argentino para las Relaciones Internacionales (CARI) (2020), "Estudio del impacto de la pandemia de Covid-19 en las relaciones internacionales y la política exterior argentina", documento de trabajo núm. 105, Buenos Aires, Consejo Argentino para las Relaciones Internacionales, <https://bit.ly/3tjYjyY>, 19 de enero de 2021.

Fabelo Concepción, C. Sunamis (2020), "De la infodemia y otros demonios", Revista Política Internacional, núm. 7, La Habana, Instituto Superior de Relaciones Internacionales Raúl Roa García, pp. 79-85, <http://rpi.isri.cu/es/node/96>, 20 de enero de 2021.

Fischer, Joschka (2020), "La política de la pandemia”, El Economista, 2 de abril, México, Nacer Global, Opinión, <https://bit.ly/3nRuLYr>, 16 de enero de 2021.

Fondo Monetario Internacional (FMI) (2020), "Políticas, política y pandemia", F\&D Finanzas y Desarrollo, 57 (2), Washington, Fondo Monetario Internacional, pp. 1-60, <https://bit.ly/3tjxE5F>, 20 de enero de 2021. 
Kissinger, Henry (2020), "La pandemia de coronavirus alterará el orden mundial para siempre", Infobae, 5 de abril, <https://bit.ly/3nJVVAA>, 20 de abril de 2020.

Lafraya, Conchi (2020), "¿Por qué no hay consenso sobre los coronabonos?”, La Vanguardia, 5 de abril, Barcelona, La Vanguardia Ediciones, Economía, <https:// bit.ly/33fDTwM>, 22 de enero de 2021.

Lange, Bernd (2020), Política comercial en tiempos de la pandemia de Covid-19, Buenos Aires, Friedrich Ebert Stiftung, <https://bit.ly/3nQolDI>, 20 de enero de 2021.

Lazarou, Elena (2020), "Las consecuencias del coronavirus en la política exterior", Parlamento Europeo, <https://bit. ly/3eRIsUh>, 20 de enero de 2021.

Lissardy, Gerardo (2020), "Coronavirus: Ios dos grandes escenarios mundiales que plantean algunos expertos para después de la pandemia", BBC News Mundo, 5 de mayo, Nueva York, Coronavirus, <https://bbc.in/33drPvE>, 20 de enero de 2021.

Maillier, Felipe (2020), "Política internacional y pandemia", El Litoral, 31 de diciembre, Buenos Aires, Por el mundo, <https://bit.ly/3ehrcHW>, 12 de enero de 2021.

Malacalza, Bernabé y Hirst, Mónica (2020), "¿Podrá reinventarse el multilateralismo?", Nueva Sociedad núm. 287, Buenos Aires, Fundación Friedrich Ebert, pp. 35-48, <https://bit.ly/3aWRVYj>, 11 de enero de 2021.

Milosevich, Mira (2020), "¿Habrá un nuevo orden mundial tras la crisis del Covid-19?", Madrid, FAES Fundación, <https://bit.ly/3h1CMsA>, 15 de enero de 2021.

Morillas, Pol (2020), "Coronavirus: entre lo global y lo nacional", Barcelona, Barcelona Centre for International Affairs, CIDOB, <https://bit.ly/3xJVzP1>, 11 de enero de 2021.
Nye, Joseph S. y Renedo, Álvaro (2020), "Las claves del poder mundial tras la Gran Epidemia", Madrid, Fundación Rafael del Pino, <https://bit.ly/2RtrMJS>, 15 de enero de 2021.

Rojas, Alberto (2020), “¿Cómo cambiará la pandemia el escenario internacional?, Boletín Observatorio $N^{\circ} 47$, Santiago de Chile, Universidad Finis Terrae, <https://bit.ly/3tgphYw>, 11 de enero de 2021.

Salvoni, Nicolás (2020), "Covid-19 y política internacional: ¿estamos ante un cambio de paradigma?", Quilmes, Universidad Nacional de Quilmes, Argentina, <https://bit.ly/3ehRVEr>, 20 de enero de 2021.

Sánchez Chumpitaz, Diego Sebastian (2020), "Covid-19: una pandemia que redibuja la política mundial”, Lima, USIL, Facultad de Derecho, <https:// bit.ly/3vH×3w1>, 20 de enero de 2021.

Torres, Jorge (2020), "La pandemia de la Covid-19: fin del orden internacional liberal y el avance del Estado autoritario en España", Madrid, Fundación Civismo, <https://bit.ly/33eaLWz>, 20 de enero de 2021.

Universidad Católica de Santa Fe (UCSF) (2020), "Covid 19 y política internacional: opinión de los miembros del OPI", Santa Fe, Universidad Católica de Santa Fe, Argentina, <https://bit.ly/3uiSiE1>, 20 de enero de 2021.

Vommaro, Pablo (2020), Las dimensiones sociales, políticas y económicas de la pandemia, Buenos Aires, CLACSO.

Recibido: 22 de enero de 2021. Reenviado: 9 de marzo de 2021. Aceptado: 12 de abril de 2021. 


\section{Norberto Emmerich}

Es doctor en Ciencia Política por la Universidad de Belgrano, Argentina. Actualmente es presidente del Centro de Estudios en Estrategia y Políticas Públicas y profesor invitado en la Universidad Autónoma de Ciudad Juárez, México, y en el Instituto de Altos Estudios Nacionales, Ecuador. Su línea de investigación actual es la geopolítica de la seguridad en América Latina. Entre sus más recientes publicaciones se destacan: Diccionario de geopolítica de la seguridad, Tarragona, Editorial Fides (2019) y Geopolitica de la Seguridad en América Latina, Buenos Aires, Editorial Biblos (2017). 
